\title{
Manajemen Wakaf dan Peranannya Pada Perguruan Tinggi
}

Gustina $^{1} \&$ Hidayatul Ihsan ${ }^{2}$

,1,2 Politehnik Negeri Padang, Indonesia

Corresponding Author: Gustina, E-mail: umgustina@pnp.ac.id

\section{ABSTRACT}

Communal ownership has proved successful in supporting and improving the welfare of society, including education. Many sectors in society that can already be supported by waqf, such as facilities of worship, hospitals, education, economic facilities and others. Study waqf in higher education was still relatively rare for Indonesia. In the world, however, there are many universities that carry out of the principle of communal ownership, such as Al-Azhar University at Cairo University of Cordoba Spain and so on. This artilce aimed to explore the application of communal ownership for higher education from management and economics. The method used literature review of books, manuscripts and publications of scientific journals. The results of the study indicated that the continuity and sustainability of the use of communal ownership in society was determined by the management of communal ownership by the manager (Nazhir) and the foundation of the trustee holder of the communal ownership.

Key words: Management Communal Ownership, Communal Ownership in Education

DOI $\quad$ https://doi.org/10.25217/ji.v4i1.407

Journal Homepage $\quad:$ http://journal.iaimnumetrolampung.ac.id/index.php/ji/

This is an open access article under the CC BY SA license

: https://creativecommons.org/licenses/by-sa/4.0/

\section{PENDAHULUAN}

Dalam sejarah Islam, waqf sangat berperan besar dalam meningkatkan kesejahteraan masyarakat. Waqf telah mendukung perbaikan dalam sarana ibadah, rumah sakit, sekolah/pendidikan, fasilitas ekonomi, pengurangan kemiskinan, dan lainnya. Bahkan tidak hanya Muslim yang menggunakan waqf ini, kaum orang - orang "Barat" juga mengadopsi beberapa prinsip waqf tersebut. Dalam literaturnya menjelaskan bahwa Sebelum abad ke-20, ada beberapa prioritas penggunaan waqf. Pertama, waqf (khususnya cash waqf) dialokasikan untuk pembangunan, pemeliharaan dan kontinuitas mesjid, kedua dialokasikan untuk sektor pendidikan termasuk gaji guru dan penyediaan sarana dan prasarana, ketiga ditujukan untuk pengentasan kemiskinan (orang kurang mampu/ yang membutuhkan). keempat, ditujukan 
untuk sektor kesehatan termasuk manajemen rumah sakit, gaji dokter dan tenaga medis, dan pendukung lainnya.

Penelitian ini lebih banyak melihat alokasi kedua, yaitu sektor pendidikan, khususnya pendidikan untuk perguruan tinggi yang dapat didukung oleh keberadaan waqf tersebut. Hal ini selaras dengan faktual yang menunjukkan biaya pendidikan tinggi yang semakin meningkat, dan juga peningkatan biaya operasi dan penyediaan kualitas sarana dan prasarana pendidikan. Disisi lain anggaran pendidikan yang tersedia dari pemerintah semakin terbatas disebabkan semakin meningkatnya jumlah institusi yang harus didanai oleh pemerintah sehingga waqf menjadi salah satu alternatif yang terbaik.

Tujuan dari penelitian ini adalah menjadikan kajian ini menjadi alternatif bagi pendidikan tinggi dalam menjalankan operasionalnya untuk hal kecukupan keuangan atau dana pendidikan terkait dengan keterbatasan anggaran pendidikan yang disediakan oleh pemerintah.

Alasan lain waqf menjadi alternatif terbaik adalah Indonesia termasuk negara berpenduduk Muslim yang padat dengan memiliki banyak potensi wakif (pemberi waqf) sehingga selalu ada peluang untuk bisa mengumpulkan dana waqf untuk keberlanjutan pendidikan ini. Melihat hal ini ada 2 alasan pentingnya penelitian ini dilaksanakan yaitu (1) menjadi alternatif keberlanjutan penyedia anggaran untuk pelaksanaan operasional perguruan tinggi, (2) menggali potensi waqif (pemberi wakaf) karena negeri kita berpenduduk muslim yang padat sehingga membuka peluang untuk memperbanyak amalan ibadah melalui tradisi wakaf ini.

Adapun perbedaan mendasar antara penelitian yang dilakukan ini dengan lainnya antara lain adalah bahwa penelitian sebelumnya hanya mengkaji potensi dari segi kajian dokumentatif saja, dengan melihat dan mempelajari studi -studi lain dari segi literature reviewnya saja. Sedangkan penelitian ini, selain mengkaji dokumentatif area, juga melakukan kajian observasi ke beberapa pelaku perguruan tinggi yang telah menerapkan sistem wakaf ini dalam alternatif anggaran pengelolaan pendidikannya. Untuk penelitian kali ini, penulis mengkhususkan observasi pada Universitas Islam Indonesia (UII) Yogyakarta sebagai salah satu pelopor perguruan tinggi berbasis wakaf di Indonesia.

Tradisi waqf di Indonesia memang sudah cukup lama, namun ketika itu masih dalam bentuk tradisional (tanah dan bangunan) sehingga penggunaannya juga terbatas. Gofar (2002) mengatakan bahwa kegiatan wakaf telah diperkenalkan di Jawa Timur, sekitar tahun 1500-an. Kemudian data catatan dari Kantor Wilayah Departemen Agama Jawa Timur dan Kantor Urusan Agama, juga menambahkan selama abad XVI ada tanah wakaf sekitar 
$20.615 \mathrm{M}^{2}$ dan jumlah ini semakin berkembang (Prihatini, Hasanah \& Widyaningsih, 2015).

Terkait dengan pendidikan tinggi, Makdisi mengutip Al-Azhar University Cairo adalah institusi pendidikan tertua yang didirikan atas aset waqf di dunia (Maksidi, 1981). Yang dimulai dengan masjid dan madrasah pada sekitar abad 10, Al-Azhar kemudian diinisiasi menjadi universitas. Hal ini telah menginspirasi banyak negara untuk melakukan hal serupa sehingga berdirilah Cordoba University Spanyol, universitas di Maroko, Irak dan lainnya.

Perkembangan yang paling fenomenal dari universitas berbasis wakaf dapat ditemukan di Turki (Mahamood, 2015). Sudah ada setidaknya 68 universitas berbasis wakaf, dan jumlahnya berpotensi meningkat setiap tahun di negara ini. Hashim (2007) mengatakan salah satu kelebihan universitas yang didanai oleh wakaf adalah mereka memiliki kebebasan untuk mengelola anggaran dan menentukan kurikulum mereka Ini juga dapat menginspirasi beberapa universitas di Malaysia untuk mulai melihat sumber-sumber potensial pendanaan pendidikan dari dana wakaf.

Kisah sukses wakaf dalam mendukung pendidikan tinggi di Al Azhar telah juga menginspirasi pendirian beberapa universitas di Indonesia. Universitas Islam Indonesia (UII) di Jogjakarta (Bamualim, 2005) dan Universitas Islam Sultan Agung (UNISSULA) di Semarang, adalah dua diantara universitas yang dimulai/ diinisiasi dari wakaf (Prihatini, 2005). Selain itu, Universitas Darussalam (UNIDA) Gontor juga berasal dari aset wakaf yang mengadopsi model Al-AzharUniversity, Cairo (Abubakar, 2005).

Ponpes Gontor Darussalam merupakan institusi wakaf yang mendapatkan dan mengumpulkan dana wakaf melalui aktivitas bisnis seperti menjalankan SME (Small and Medium Entrepreneurship), membangun toko konstruksi, restoran, toko obat, toko alat tulis dan lainnya. Saat ini SME mereka telah mencapai 31 units pada 2012. bisnis ini langsung dijalankan oleh para guru/ ustazd/ustadzah. Sekarang Ponpes Gontor Darussalam telah memiliki university sendiri, yaitu Universitas Darussalam (UNIDA), yang saat ini telah memiliki ribuan mahasiswa. Bentuk aktivitas bisnis ini dijalankan agar terjadi kemandirian dalam hal keuangan bagi UNIDA sehingga tidak bergantung pada student fee saja. Selain itu mereka juga menyewakan tanah wakaf yang mereka miliki kepada para petani disekitarnya dengan menggunakan kontrak ijarah dan musharakah dimana harga sewa ini tergantung pada tingkat kesuburan tanah tersebut (Hilmiah et al. 2013). Dana yang diperoleh dari penyewaan ini akan menambah pada asset wakaf yang Ponpes gontor miliki.

Permasalahan yang akan diselesaikan dalam penelitian ini adalah apakah waqf dengan manajemennya dapat menjadi alternatif dalam mendukung 
pendidikan tinggi. Untuk memudahkan pelaksanaan penelitian ini maka tujuan utamanya adalah untuk mengekplorasi manajemen waqf dalam mendukung berlangsungnya pendidikan tinggi (khususnya menjadi alternatif kecukupan anggaran penyelenggaraan pendidikan di perguruan tinggi, seperti yang telah juga di tulis di pendahuluan paper ini). Selain itu juga melihat bagaimana pengelolaan aset waqf tersebut untuk keberlangsungan dan peningkatannya.

\section{METODE PENELITIAN}

Penelitian ini menggunakan pendekatan kualitatif dengan studi kasus sebagai design penelitian. Design studi kasus dipilih karena memungkinkan peneliti memperoleh pengetahuan yang mendalamakan isue yang ditemui dilapangan, untuk kemudian bisa merumuskan kebiajakan sebagai salah satu luarannya (Yin, 1994). Dari sisi paradigma, studi kasus yang ada dalam penelitian ini tergolong kepada interpretive yang membutuhkan pemahaman dan interpretasi dari peneliti terhadap personal-personal yang diteliti di lapangan.

Peneliti memilih Yayasan Badan Wakaf Universitas Islam Indonesia Yogyakarta selanjutnya disingkat BW UII. Alasan untuk memilih kasus ini adalah karena BW UII adalah salah satu universitas tertua yang dimulai dari wakaf di Indonesia miliki (Bamualim, 2005). Selain itu kemudahan untuk mengakses data- data penelitian juga merupakan salah satu alasan dengan keterbukaan manajemen mutawalli yang cukup baik (Prihatini, Hasanah, Wirdyaningsih, 2005). Pada dasarnya, pembenaran untuk pemilihan kasus ini tidak dapat dilihat sebagai metode sampling. Dalam pemilihan kasus, penelitian kualitatif lebih didasarkan pada aspek teoretis, bukan metode sampling statistic (Erikssen \& Kovalainen, 2008). Dalam penelitian ini, Peneliti menggunakan berbagai metode yaitu melalui wawancara mendalam, observasi dan tinjauan dokumen. Melalui penggunaan berbagai metode ini diharapkan dapat membantu peneliti dalam memahami lebih baik tentang masalah yang diteliti. Selanjutnya, data dianalisis melalui analisis tematik.

\section{HASIL PENELITIAN DAN PEMBAHASAN}

\section{Profil Badan Wakaf UII Yogyakarta}

Badan Wakaf UII sebagai suatu badan hukum yang didirikan berdasarkan hukum Negara Republik Indonesia, berkedudukan di Yogyakarta, beralamat di Jalan Cik Di Tiro Nomor 1 Yogyakarta, untuk pertama kalinya didirikan dengan Akta Nomor 19 tanggal 22 Desember 1951 yang dibuat oleh dan 
dihadapan R.M. Wiranto, Notaris di Yogyakarta, sebagaimana telah beberapa kali diubah terakhir dengan Akta No. 02 tanggal 15 Desember 2014 yang dibuat oleh dan dihadapan Dewi Karomah, SH, Notaris di Sleman, dan telah dinyatakan dicatat dalam daftar yayasan berdasarkan surat Kementerian Hukum dan Hak Azasi Manusia RI No. AHU-AH.01.06.65 tanggal 7 Januari 2015 (Yayasan Badan Wakaf Universitas islam Indonesia).

Kegiatan pokok Pengurus Yayasan Badan Wakaf UII bergerak di bidang Pengembangan Pendidikan, Pengembangan Unit Usaha dan Pemberdayaan Masyarakat. Dalam Pengembangan Pendidikan Yayasan Badan Wakaf UII menyelenggarakan Pendidikan Tinggi (Universitas Islam Indonesia), Pendidikan Menengah (SMA UII) dan Pendidikan Anak Usia Dini (TK "Sultan Agung BW UII" dan Play Group Badan Wakaf UII).

Khususnya untuk pendidikan tinggi, pilihan ini bagi Badan Wakaf UII bertujuan agar umat Islam dapat mengikuti perkembangan dunia pendidikan yang dinamis sehingga dapat memerdekakan masyarakat dari kebodohan dan menghasilkan pemimpin-pemimpin nasional yang mumpuni (Huda, 2014). Selain itu juga diharapkan dapat menghasilkan intelektual yang menguasai pengetahuan, teknologi serta agamis sekaligus. Hal ini bertujuan untuk membangun keseimbangan dunia dan akhirat.

\section{Sumber Aset Wakaf Badan Wakaf UII/ Fundraising}

Sejak Badan Wakaf UII didirikan, mereka memang lebih banyak menanamkan asset wakaf dalam bentuk pengembangan pendidikan. Sampai hari ini, perkembangan Universitas Islam Indonesia sangat maju pesat. Mereka telah melakukan penggalangan dana wakaf untuk terus meningkatkan mutu pendidikan di universitas ini. Hal ini tampak jelas bahwa wakaf dapat dijadikan andalan dalam sisi pembiayaan untuk sebuah infrastruktur seperti perguruan tinggi.

Dalam hal pengumpulan dana wakaf, Badan Wakaf UII telah melakukan berbagai upaya penggalangan dana/daya dalam rangka melakukan terobosan agar aset dan potensi kelola wakaf yang besar dapat dikembangkan. Penggalangan tersebut bisa dalam berbagai bentuk seperti pendanaan yang bersifat tunai maupun non tunai serta adanya jaringan kerjasama dalam upaya memproduktifkan potensi aset wakaf yang ada (Bamualim, 2005). Aktifitas ini dikenal dengan fundraising. Hal ini selaras dengan penelitian yang dilaksanakan oleh (Mahamood \& Rahman, 2005).

Aktivitas fundraising dapat diartikan sebagai serangkaian kegiatan dalam rangka penggalangan dana dan daya lainnya dari masyarakat yang akan digunakan untuk membiayai program dan kegiatan operasional lembaga 
sehingga mencapai tujuan dan untuk mengembangkan usaha-usaha sosial (social enterprise). Seperti dikutip oleh Michael dalam Huda (2015) Kegiatan fundraising yang dilakukan Badan Wakaf UII tidak hanya dalam konteks penghimpunan sumber-sumber aset wakaf namun juga sebagai jalan untuk memproduktifkan aset-aset wakaf yang ada yang selama ini belum optimal. Dari kegiatan ini diharapkan perkembangan Badan Wakaf UII sebagai pengelola aset wakaf dapat mencapai tingkat kemandirian dan keberlanjutan sehingga dapat memberikan kemaslahatan atatu manfaat lebih banyak kepada uma atau masyarakat.

Dari hasil beberapa penelitian, ada beberapa cara yang digunakan BW UII untuk kegiatan fundraising ini, yaitu sebagai berikut:

(1) Menghimpun dari sumber-sumber wakaf yang tersedia. Hal ini dilakukan dengan cara mengirimkan proposal kepada calon waqif, berkampanye melalui media/ iklan untuk nadzir yang memiliki media massa atau keterkaitan kerjasama dengan itu, dana CSR (dana-dana sosial yang dikeluarkan oleh perusahaan) dan melalui jaringan alumni atau kemahasiswaan. Cara ini sesuai dengan hasil penelitian (Mahamood \& Rahman, 2014).

Membangun unit-unit bisnis. BW UII memproduktifkan aset wakaf yang ada dengan cara membangun unit-unit bisnis yang menghasilkan pendapatan bagi nadzir. Hal itu dilakukan dengan penjualan produk, penyewaan sarana / fasilitas, kerjasama dengan usaha/ perusahaan, atau mendirikan CV atau PT. Hasil penelitian ini selaras dengan yang dilakukan oleh (Hilmiah dkk, 2013).

Ada banyak CV atau PT yang telah didirikan oleh BW UII, diantaranya:

a) PT. Unisia Medika Farma ( RS “JIH")

b) PT. Radio Prima Unisi (Radio Unisi)

c) PT. Unisia Polifarma (Apotik UII Farma dan Poliklinik)

d) PT. Puri Kencana Rizki Mulia (SPBU Tuntang Salatiga dan minimarket)

e) PT. Radio Media Umat (Radio Dakwah)

f) PT. BPRS Unisia Insan Indonesia (BPRS UII)

g) PT. Unisia Kreasi Sejahtera (Hotel Unisi)

h) PT. Bank UII

i) Percetakan dan penerbitan UII

(2) Memberdayakan hasil wakaf masyarakat atau umat. Artinya, wakaf yang disalurkan kepada umat tidak hanya untuk kepentingan konsumtif, namun lebih diproduktifkan sehingga juga dapat memberikan income/ pendapatan maupun manfaat lainnya kepada penerima. BW UII berinvestasi produktif dalam rencana rumah serba guna untuk pengembangan ekonomi produktif, 
tanaman produktif (bidang pertanian), tanaman makanan ternak dan tanaman obat.

Hasil kegiatan fundraising (penggalangan dana wakaf) kemudian ditanamkan atau dikembangkan untuk kegiatan pendidikan yang ada dalam pengelolaan BW UII. Khususnya untuk Institusi perguruan tinggi (UII), generate income yang ada sangat mendukung perkembangan operasional dan infrastruktur kampus, selain dari dana /sumbangan SPP mahasiswa. Hal ini menyebabkan UII menjadi mandiri dalam finansial, walaupun pemerintah tetap memberikan aliran dana secara periodik. Inilah salah satu keunggulan Institusi perguruan tinggi berbasis aset wakaf, mereka memiliki kebebasan dalam pengelolaan manajemennya terutama dalam hal keuangan.

\section{Manajemen Aset Wakaf Pada BW UII}

Melihat banyak dan besarnya BW UII dengan aset-asetnya, memperlihatkan kepada kita bahwa nadzir telah melakukan pekerjaannya dengan sangat luar biasa. Hari demi hari aset wakaf yang ada terus bertambah sehingga tentu saja nantinya akan memberikan manfaat dan kemaslahatan lebih besar kepada masyarakat/ umat.

Salah satu kegiatan pengelolaan yang penting pada BW UII adalah kegiatan unit bisnis (dengan melakukan investasi dan reinvestasi dalam usaha produktif) sehingga lambat laun harta/ aset wakaf akan meningkat. Seperti terlihat dalam bagan berikut:

\section{Gambar (Figure) 1. \\ Peningkatan Aset Wakaf}

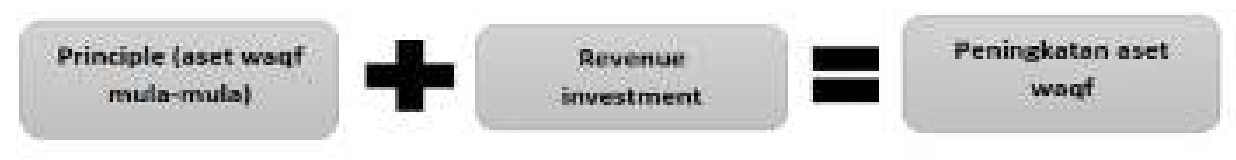

Pada gambar (figure) 1. terlihat bahwa aset wakaf yang diterima oleh nadzir, dalam bentuk tanah, bangunan, uang ataupun bentuk lainnya, dikelola produktif oleh nadzir. Salah satu caranya adalah dengan dinvestasikan, baik dalam bentuk bangunan kembali ataupun reinvestasi ke dalam unit bisnis. Dari reinvestasi tersebut akan diperoleh benefit (revenue investment) sehingga ini akan menambahkan jumlah aset semula. Melalui cara ini peningkatan jumlah aset wakaf akan terjadi berulang-ulang.

Banyaknya unit bisnis yang dikelola oleh BW UII sebagai bentuk pertanggungjawaban atas amanah pengelolaan wakaf yang dititipkan para 
waqif menjadikan para nadzir pejuang tangguh yang ulet sehingga usahausaha yang dilakukan membuahkan revenue baik berupa pendapatan atau income ataupun hanya berupa pertambahan manfaat yang dapat dinikmati oleh umat atau masyarakat. Dari diskusi diatas, gambar berikut menunjukkan banyaknya aset-aset yang dikelola BW UII.

\section{Gambar (Figure) 2.}

Aset-aset bisnis YBW UII

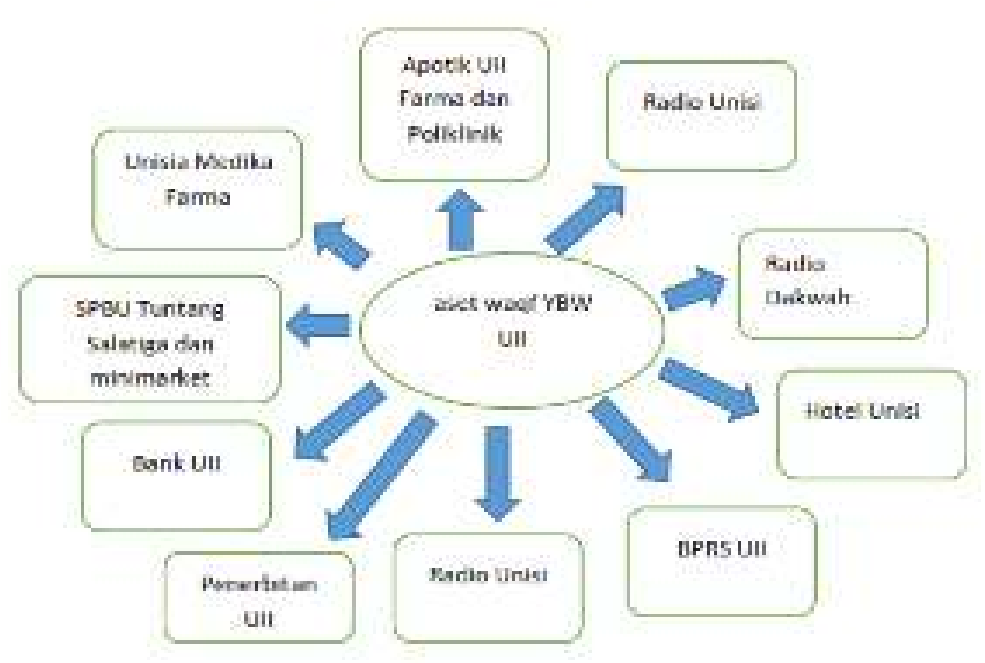

Gambar (Figure) 2. menunjukkan, dalam menjalankan reinvestasi aset wakaf yang ada, BW UII telah berhasil mendirikan dan mengoperasionalkan beberapa unit bisnis yang bergerak di berbagai sektor seperti cafe dan minimarket, perbankan atau BPR, radio, apotik dan rumah sakit, penerbitan dan perhotelan. Dari unit bisnis ini diharapkan BW UII mendapatkan peghasilan income/ pendapatan yang kontinu sehingga BW UII sebagai nadzir (pengelola) dapat mengembangkan aset wakaf ini menjadi berdayaguna dan manfaat yang lebih besar.

\section{Peranan wakaf (beserta asetnya) dalam menunjang Perguruan Tinggi}

Seperti yang sudah didiskusikan diatas, manfaat dan peranan yang dimainkan oleh wakaf sangat besar terutama dalam hal pengentasan kemiskinan (helping needy), peningkatan pendidikan (upgrading education), sarana dan prasarana sosial (social infrastructure), dan peningkatan ekonomi (upgrading economic) (Kahf, 2007).

Dalam hal pendidikan tinggi, wakaf yang dikelola BW UII (kebanyakan harta yang diterima sebagai wakaf adalah tanah) dipergunakan untuk 
pembangunan universitas (dalam hal ini UII) dan sekolah yang tersebar dibeberapa lokasi. Rata-rata lokasinya masih berada di Jawa. Secara teknis, UII yang didirikan BW UII dapat membiayai pengeluaran operasional institusi seperti biaya pengajar, biaya administrasi perkantorannya, riset, infrastruktur pendidikan dan yang berhubungan dengan proses belajar mengajar diperguruan tinggi. Namun karena biaya operasinal ini semakin meningkat, pihak BW UII tidak memberikan fasilitas pendidikan kepada mahasiswa secara cuma-cuma.

Manjemen BWUII beranggapan bahwa pengelolaan pendidikan membutuhkan biaya,karena itu tidak adasalah nyaji kamereka mengambil sedikit surplus dari pengelolaan itu. Namun karena biaya operasinal ini semakin meningkat, pihak BW UII tidak memberikan fasilitas pendidikan kepada mahasiswa secara cuma-cuma. Manajemen BWUII beranggapan bahwa pengelolaan pendidikan membutuhkan biaya, karena itu tidak ada salahnya jika mereka mengambil sedikit surplus dari pengelolaan itu.

Selain itu, baru-baru ini BW UII membangun sebuah rumah sakit internasional sebagai salah satu unit bisnisnya. Rumah sakit ini diharapkan dapat berkontribusi secara finansial dan akademis bagi universitas. Secara finansial adalah dalam haluan yang diperoleh dari rumah sakit sedangkan secara akademis mendukung mahasiswa kedokteran yang sedang melakukan studi praktisnya. Dana wakaf yang terkumpul diperuntukkan untuk tiga tujuan yaitu: pembangunan rumah sakit, pembangunan asrama mahasiswa, dan pengembangan kampu sterpadu UII. Hasil penelitian ini selaras dengan apa yang dilakukan oleh (Hussin, Rashid Yaakub, 2016),

\section{KESIMPULAN}

Wakaf merupakan kegiatan amalan yang telah ditunaikan Muslim sejak zaman Rasulullah yang memiliki dampak besar dalam kehidupan masyarakat. Manfaat dari wakaf selain untuk memenuhi manfaat sosial dan ibadah (pembangunan masjid dan infrastuktur lain), rumah sakit, pengentasan kemiskinan, perekonomian (BPR dan Bank), dan lainnya.

Aset wakaf yang terkumpul baik berupa barang (tanah, dll) maupun wakaf tunai, dapat dijadikan pilar yang kuat untuk meningkatkan dunia pendidikan di Indonesia. Hal ini sudah dibuktikan oleh Badan wakaf UII Yogyakarta yang telah berhasil menjadi nadzir dengan mengembangkan produktifitas pada harta wakaf tersebut sehingga aset wakaf semakin berkembang dari masa ke masa. Diharapkan dengan berkembangnya dan bertambahnya aset wakaf ini 
akan meningkatkan; pula manfaat yang dapat dinikmati oleh masyarakat/ umat yang berada disekitarnya. 


\section{DAFTAR PUSTAKA}

Abubakar, I. (2005a). Pengelolaan wakaf di pondok modern Gontor Ponorogo: menjaga kemandirian civil society. In Bamualim, C.S. and Abubakar, I. (ed.), Revitalisasi filantropi Islam: Studi kasus lembaga zakat dan wakaf di Indonesia (pp. 217 - 254). Jakarta: Pusat Bahasa dan Budaya, Universitas Islam Negeri Jakarta.

Abubakar, I. (2005b). Pelembagaan wakaf di pesantren Tebuireng Jombang: Sebuah upaya merespon kebutuhan akan perubahan. In Bamualim, C.S. and Abubakar,I (ed.), Revitalisasi filantropi Islam. Studi kasus lembaga zakat dan wakaf di Indonesia (pp. 283 - 297). Jakarta: Pusat Bahasa dan Budaya, Universitas Islam Negeri Jakarta.

Asuhaimi, F.A, Shafii, Z and Alias, M.H (2013), The Effort Of Selected Public Universities In Developing Awqaf Properties Using Cash Waqf Instrument", Journal of Chemical Information and Modelling. Vol 53 (9), pp 1689-1699

Bamualim, C.S (2005), Badan Wakaf Universitas Islam Indonesia (UII) Yogyakarta: Wakaf untuk modernisasi perguruan tinggi Islam. In Bamualim C.S and Abubakar, I (eds), Revitalisasi Filantropi Islam : Studi kasus lembaga zakat dan wakaf di Indonesia (pp 255-281). Jakarta: Pusat Bahasa dan Budaya, Universitas Islam Negeri Jakarta.

Eriksson, P. \& Kovalainen, A. (2008). Qualitative methods in business research. Los Angeles: Sage publications.

Gofar, A. (2002). Keberadaan undang-undang wakaf di dalam perspektif tata hukum nasional. Mimbar Hukum, 57, 72-82.

Hashim,R. (2007). Intellectualism in higher Islamic traditional studies: implications for the curriculum. The American journal of Islamic social sciences. Vol. 10, No 3, pp. 92-115.

Hilmiyah, N, Mohm Shafiai, M.H, Ahmad, S, Ramzi, M and Che Hariff, M.R, (2013), “Wakaf Produktif Dalam Pembangunan Pendidikan : Kajian Di Pondok Modern Darussalam Gontor, Indonesia", Persidangan Kebangsaan Ekonomi Malaysia VII (PERKEM VII), vol 3, pp 1302-1314

Huda, Miftahul (2014), Manajemen Fundraising Wakaf: Potret Yayasan Badan Wakaf Universitas Islam Indonesia Yogyakarta dalam Menggalang Wakaf : Justisia Islamica, hal 1-26

Hussin, R, Rashid, R.A. and Yaakub. N.I, (2016)," Exploratory Study On Waqf Implementation In Malaysian Public And Private Universities: With Special 
Reference To Turkish Universities", Proceeding Kual Lumpur International Business, Economics And Law Conference 9, pp 399-409

Kahf, Monzer. (2007). The role of waqf in improving the ummah welfare. Paper presented at the Singapore international waqf conference 2007, Singapore.

Makdisi, G. (1981), The Rise of Colleges, Edinburgh University Press, Edinburgh.

Mahamood,S.M. dan Ab. Rahman, A. (2014)," Waqf Financing For Higher Education: Contemporary Funding Application In Some Selected Countries", Prosiding Pelestarian Institusi Wakaf: Memperkasa Pendidikan Tinggi Negara, pp 263-278

Mahamood,S.M. dan Ab. Rahman, A. (2015). Financing universities through waqf, pious endowment: is it possible? Humanomics, Vol 31, No 4, pp.430-453

Michael, Norton, 2002, Menggalang Dana: Pedoman bagi LembagaSwadaya Masyarakat, Jakarta: Yayasan Obor

Prihatini, F., Hasanah, U., and Wirdyaningsih. (2005). Hukum Islam zakat dan wakaf, teori dan prakteknya di Indonesia. Jakarta : Badan Penerbitan Fakultas Hukum Universitas Indonesia.

Richard, Holloway,(2002), Menuju Kemandirian Keuangan, Penerbit Yayasan Obor : Jakarta, hal 21-22

Suparman, (2009), Strategi Fundraising Wakaf Uang, Jurnal Wakaf dan Ekonomi Islam, Vol. II, No. 2

Yin, R.K (1994), Case Study Research: Design And Methods. Thousand oaks : sage publications

(https:/ / www.jobstreet.co.id/en/companies/826374-yayasan-badan-wakafuniversitas-islam-indonesia taken 23 august 2017, 23.19). 